\title{
PRODUÇÃO E QUALIDADE DE ROSAS EM RAZÃO DE DOSES DE BORO APLICADAS NO SUBSTRATO(1)
}

\author{
Luiz Antônio Zanão Júnior ${ }^{(2)}$, Maristela Pereira Carvalho-Zanão ${ }^{(3)}$, Renildes Lúcio \\ Ferreira Fontes $^{(4)}$ \& José Antônio Saraiva Grossi ${ }^{(5)}$
}

\begin{abstract}
RESUMO
Muitos trabalhos têm demonstrado os efeitos da aplicação do boro (B) em variadas culturas; entretanto, poucos registros demonstram seus efeitos na produção de rosas. Objetivou-se com este experimento avaliar os efeitos de doses de B na produção e qualidade de rosas (Rosa hybrida $\mathrm{cv}$. Shiny Terrazza ${ }^{\circledR}$ ) em vaso. Os tratamentos foram cinco doses de $\mathrm{B}\left(0,1,4,8 \mathrm{e} 16 \mathrm{mg} \mathrm{kg}^{-1}\right)$, aplicadas no substrato, em delineamento de blocos casualizados, com cinco repetições. Foram avaliados: número de flores por planta; número de folhas por haste floral; produção de matéria seca de raízes, folhas e flores; altura da planta; número de dias para o florescimento; comprimento do botão floral; e diâmetro e longevidade floral. Além disso, foram determinados os teores foliares de clorofila total e B e os sintomas de toxidez desse elemento. Verificou-se efeito significativo das doses de $B$ na maioria das variáveis avaliadas, excetuando-se a altura das plantas, o número de flores por planta, a longevidade floral e a produção de matéria seca de raízes. $O$ teor foliar de $\mathrm{B}$ aumentou linearmente em função das doses desse elemento. Houve incremento na produção e qualidade das flores com a aplicação do $B$, com redução do número de dias para o florescimento. Foram verificados sintomas de toxidez causado pelo B a partir da dose de $4 \mathrm{mg} \mathrm{kg}^{-1}$. Esses sintomas foram caracterizados por manchas do tipo encharcamento, iniciando nas margens do limbo foliar, com essas evoluindo para clorose e posterior necrose; na maior dose ocorreu queda de folhas. Essa queda foi responsável pela diminuição do número de folhas por haste no final do ciclo, a partir da dose de $8 \mathrm{mg} \mathrm{kg}^{-1}$ de $\mathrm{B}$. As plantas com sintomas de toxidez apresentaram teores foliares de $B$ acima de $200 \mathrm{mg} \mathrm{kg}^{-1}$, enquanto as sadias (controle), de 65 a $89 \mathrm{mg} \mathrm{kg}^{-1}$.
\end{abstract}

Termos de indexação: Rosa hybrida, micronutriente, ácido bórico, floricultura.

(1) Recebido para publicação em 7 de novembro de 2012 e aprovado em 13 de novembro de 2013.

(2) Pesquisador, Instituto Agronômico do Paraná - IAPAR. Bolsista da Fundação Araucária. Caixa Postal 02. CEP 85825-00 Santa Tereza do Oeste (PR). E-mail: lzanao@iapar.br

(3) Doutoranda em Agronomia, UNIOESTE, Campus Marechal Cândido Rondon. Rua Pernambuco, 1777. CEP 85960-000 Marechal Cândido Rondon (PR). E-mail: carvalhozanao@iapar.br

(4) Professor, Departamento de Solos, Universidade Federal de Viçosa - UFV. Av. P.H. Rolfs, s/n. CEP 36570-900 Viçosa (MG). Email: renildes@ufv.br

(5) Professor, Departamento de Fitotecnia, UFV. E-mail: jgrossi@ufv.br 


\title{
SUMMARY: PRODUCTION AND QUALITY OF ROSES AS AFFECTED BY BORON FERTILIZATION
}

\begin{abstract}
Many studies have shown the effects of boron (B) application on various crops; however, results on roses are scarce. The aim of this experiment was to evaluate the effects of $B$ on the production and quality of roses (Rosa hybrida Shiny Terrazza ${ }^{\mathbb{R}}$ ) under controlled conditions. Treatments consisted of five rates of $B\left(0,1,4,8\right.$ and $\left.16 \mathrm{mg} \mathrm{kg}^{-1}\right)$ applied in the substrate in a randomized block design with five replicates. We evaluated the cycle; number of flowers per plant; number of leaves per flower stem; dry matter production of roots, leaves and flowers; plant height; length of the floral bud; and flower diameter and longevity. In addition, total chlorophyll and $B$ content in the leaves and symptoms of $B$ toxicity in the plants were also determined. There was a significant effect of $B$ application rates on most of the variables, with the exception of plant height, number of flowers per plant, flower longevity, and root dry matter production. Leaf B content increased in a linear manner with increasing application rates of $B$ in the range of 0 to $16 \mathrm{mg} \mathrm{kg}^{-1}$. There was an increase in flower production and quality with the application of $B$, and a reduction in the number of days to flowering. Boron toxicity symptoms were observed at B rates higher than $4 \mathrm{mg} \mathrm{kg}^{-1}$. These symptoms were characterized by soaked spots beginning at the edges of the leaf blade, with the spots evolving to chlorosis and subsequent necrosis. At the highest rate of B application, there was dropping of leaves. This leaf dropping was responsible for the decreased number of leaves per floral stem at the end of the cycle as of $B$ application rates of $8 \mathrm{mg} \mathrm{kg}^{-1}$. Plants showing symptoms of toxicity had leaf $B$ contents above $200 \mathrm{mg} \mathrm{kg}^{-1}$, while healthy plants (control) had B contents ranging from 65 to $89 \mathrm{mg} \mathrm{kg}^{-1}$.
\end{abstract}

Index terms: Rosa hybrida, micronutrient, boric acid, floriculture

\section{INTRODUÇÃO}

A produção de flores vem apresentando expressivo crescimento no Brasil, sendo uma opção de investimento para muitos agricultores e, por causa das suas peculiaridades, exige pesquisas e técnicas adaptadas à sua realidade, sendo a adubação um fator de impacto sobre a produtividade, qualidade e longevidade das flores (Nell et al., 1997). Seu manejo adequado pode ser um diferencial para se alcançar maior sucesso na acirrada competição existente na floricultura. A influência dos micronutrientes é notada tanto no aspecto quantitativo do crescimento e no desenvolvimento das plantas quanto na expressão dos atributos qualitativos como comprimento e diâmetro da haste, cor e longevidade floral (Marschner, 1995; Ahmad et al., 2010). Isso indica que o manejo adequado da adubação com micronutrientes pode contribuir para garantir maior retorno econômico ao produtor. Particularmente para a cultura da roseira, Savvas (2002) mencionou que a produção e a qualidade das rosas são influenciadas pelo manejo da adubação. O boro é um micronutriente envolvido em muitos processos fisiológicos nas plantas, os quais são prejudicados tanto por sua deficiência quanto por sua toxidez. Transporte de açúcares; síntese e estruturação da parede celular; metabolismo fenólico do RNA, de carboidratos, de auxinas; manutenção da integridade da membrana plasmática; atividade da ATPase; respiração; e lignificação são exemplos de processos em que o B atua (Dordas \& Brown, 2000; Goldbach et al., 2001; Bolaños et al., 2004; Camacho-Cristóbal et al., 2008).
A deficiência de $\mathrm{B}$ nas plantas cultivadas é comum no Brasil, onde tem provocado redução na produtividade em algumas culturas (Mariano et al., 2000), e em outros 80 países, onde foi verificada deficiência em 132 culturas (Shelp \& Brown, 1995). Na recomendação da dose de aplicação de B, exige-se cautela uma vez que o intervalo entre a sua concentração adequada para as plantas e a que pode provocar toxidez é bastante estreita (Havlin et al., 2005), variando entre espécies e até entre genótipos de uma mesma espécie (Gonçalves \& Valeri, 2001). A toxidez provocada pelo excesso, apesar de ser menos comum que a deficiência, pode ocorrer em certas situações como em solos salinos de regiões áridas e em solos agrícolas que receberam aplicação de B em excesso (Gupta, 1993). Dechen \& Nachtigall (2006) afirmaram que a toxidez de B é tão grave quanto sua deficiência.

O sintoma visual típico de toxidez de B na maioria das espécies é a clorose nas margens de todo o limbo foliar, que evolui para necrose e desfolhamento em casos de toxidez severa (Gupta, 1983). Essa localização dos sintomas reflete a distribuição do B na maioria das plantas, uma vez que esse elemento tende a se acumular nas folhas em razão do fluxo transpiratório (Nable et al., 1997; Roessner et al., 2006). A concentração do B nos tecidos das partes necrosadas é elevada em comparação à sua concentração nos tecidos vizinhos (Salvador et al., 2003).

Muitos trabalhos têm demonstrado os efeitos da aplicação do B em variadas culturas; entretanto, quase não há registros que demonstrem seus efeitos na produção de rosas. O objetivo deste trabalho foi avaliar 
os efeitos de doses de B na produção e qualidade de rosas (Rosa hybrida cv. Shiny Terraza ${ }^{\circledR}$ ), cultivadas em vaso.

\section{MATERIAL E MÉTODOS}

O experimento foi conduzido em casa de vegetação do setor de Floricultura do Departamento de Fitotecnia da Universidade Federal de Viçosa.

Roseiras (Rosa hybrida cv. Shiny Terrazza ${ }^{\circledR}$ ) com flores de coloração amarela, obtidas a partir de estacas de mudas matrizes de área de produção comercial com dois pares de folhas completas foram individualmente transplantadas para vasos plásticos com capacidade de $0,8 \mathrm{~L}$, contendo substrato comercial Plantmax ${ }^{\circledR}$. Foram avaliados os teores solúveis e totais de B pelo método holandês 1:1,5 (Sonneveld \& Elderen, 1994), com determinação por espectrometria de emissão óptica em plasma (ICP-OES). O substrato apresentou teor solúvel de $0,2 \mathrm{mg} \mathrm{L}^{-1}$ e $<1,0 \mathrm{mg} \mathrm{kg}^{-1}$ de teor total de B. Após o transplantio e a aclimatação das mudas na casa de vegetação, procedeu-se a poda, deixando-se duas folhas completas por haste. A irrigação foi realizada diariamente, e a fertirrigação, duas vezes por semana, utilizando-se $50 \mathrm{~mL}$ de uma solução de macro e micronutrientes por vaso (Zanão Júnior et al., 2009).

Os tratamentos foram cinco doses de B $(0,1,4,8$ e $16 \mathrm{mg} \mathrm{kg}^{-1}$ ), aplicadas no substrato, em delineamento de blocos casualizados, com cinco repetições. A fonte utilizada foi o ácido bórico. Cada parcela experimental foi constituída por um vaso com uma planta com duas hastes florais.

Após a poda, quando as brotações atingiram aproximadamente $10 \mathrm{~cm}$, com pelo menos uma folha expandida por haste, fez-se a aplicação única do B no substrato.

$\mathrm{Na}$ avaliação, utilizou-se a escala de estádio de abertura floral proposta por Cushman et al. (1994), com os seguintes critérios para os estádios: 1, para botão floral fechado; 2 , para pétalas fechadas e sépalas abertas; 3 , para início de abertura das pétalas (tradicional estádio de botão floral); 4, para diversas pétalas abertas; 5 , para botão floral completamente aberto; e 6, para fim da vida de vaso da flor (mais de uma pétala murcha e, ou, escurecida).

No estádio 2 de abertura floral, foram avaliados a altura da planta, medida a partir da borda superior do vaso até a extremidade do botão floral, o número de folhas por haste floral e flores da planta e o comprimento do botão floral.

O número de dias para o florescimento foi determinado pelo número de dias entre a poda e o estádio 2, e a longevidade floral, pelo número de dias entre o estádio 2 e o 6 de abertura floral.
A determinação de clorofila total foi realizada a partir do método colorimétrico descrito por Porra et al. (1989). Foram utilizados discos foliares de hastes do terço médio de plantas com flores em senescência, correspondendo ao estádio 6 de abertura floral proposto por Cushman et al. (1994). Os discos $\left(1,414 \mathrm{~cm}^{2}\right)$ coletados entre as nervuras secundárias, excluindose a nervura principal, foram imersos em $25 \mathrm{~mL}$ de acetona $\left(800 \mathrm{~mL} \mathrm{~L}^{-1}\right)$ e colocados no escuro por quatro dias, à temperatura média de $3{ }^{\circ} \mathrm{C}$. As leituras de absorbância nos extratos para a análise de clorofila foram feitas em espectrofotômetro, determinando-se as absorbâncias nos comprimentos de onda de 645 e $663 \mathrm{~nm}$. O cálculo utilizado para a quantificação do pigmento foi:

Clorofila total $(a+b)=17,76 \mathrm{~A}^{645}+7,34 \mathrm{~A}^{663}$

em que: $\mathrm{A}^{663}=$ absorbância a $663 \mathrm{~nm}$; e $\mathrm{A}^{645}=$ absorbância a $645 \mathrm{~nm}$.

As folhas, flores e raízes foram destacadas da planta, lavadas com água destilada, secas em estufa de circulação forçada de ar a $65{ }^{\circ} \mathrm{C}$ até atingirem massa constante, determinando-se a produção de matéria seca dessas partes da planta.

O número de folhas por haste floral foi especificado, contando-se apenas as folhas com cinco folíolos ou mais. $\mathrm{O}$ diâmetro das flores e a produção de matéria seca das flores foram avaliados no estádio 5 de abertura floral.

As folhas foram moídas em moinho tipo Willey com peneira de $0,84 \mathrm{~mm}$ e calcinadas a $550{ }^{\circ} \mathrm{C}$. A dosagem do $\mathrm{B}$ foi realizada pelo método colorimétrico, com o reagente azometina-H (Wolf, 1974).

Os resultados foram submetidos à análise de variância, sendo ajustadas equações de regressão para as variáveis avaliadas em função das doses de B. Utilizou-se o aplicativo Assistat (Silva \& Azevedo, 2006).

\section{RESULTADOS \& DISCUSSÃO}

Verificou-se efeito significativo das doses de B em quase todas as variáveis avaliadas, excetuando-se a altura das plantas, o número de flores por planta, a longevidade floral e a produção de matéria seca de raízes (Figuras 1a-f e $2 \mathrm{a}-\mathrm{f}$ ). O número de folhas por haste floral no florescimento, a produção de matéria seca de folhas e flores, o teor de clorofila total, o comprimento do botão floral, o diâmetro floral e o número de dias para o florescimento ajustaram-se ao modelo quadrático em função da aplicação das doses de B.

A altura média das plantas foi $24,58 \mathrm{~cm}$ (Figura 1a) e não diferiu em função das doses de $B$ adicionadas ao substrato. Esse resultado coincide com o obtido por Furlani et al. (2003), os quais, também, não observaram diferenças significativas na altura de 
cultivares de trigo crescidos em solução nutritiva com diferentes doses de B.

A produção de matéria seca de raízes se manteve uniforme em resposta ao aumento da dose de B (Figura 1b), confirmando os resultados de Silva (2007), o qual, na cultura da mamoneira, também não observou resposta às doses de $\mathrm{B}$ na produção de matéria seca de raízes. No entanto, Fageria (2000) relatou que a dose adequada de B para o desenvolvimento do sistema radicular varia com a cultura, tendo encontrado adequação na faixa de 0,4 a $2,9 \mathrm{mg} \mathrm{kg}^{-1}$ para trigo, arroz e milho, com a primeira cultura requerendo mais $\mathrm{B}$ para o desenvolvimento do sistema radicular do que as outras duas.

Houve incremento no número de folhas por planta até a dose estimada de $1,04 \mathrm{mg} \mathrm{kg}^{-1}$ de B com a qual foi constatada a produção de 8,9 folhas por planta (Figura 1c). Com a maior dose de B (16 mg kg-1), o número de folhas por planta foi 6,5 , o que evidenciou queda de folhas nas plantas quando se usou dose elevada de B. Segundo Gupta (1983), em caso de toxidez severa provocada pelo excesso de B, há queda das folhas. Com relação ao crescimento das plantas, a maior produção de matéria seca nas folhas (3,33 g) foi obtida com a dose de $0,44 \mathrm{mg} \mathrm{kg}^{-1}$ de B (Figura 1d), havendo redução de quase $16 \%$ na matéria seca de folhas produzidas nas plantas cultivadas no substrato adubado com $16 \mathrm{mg} \mathrm{kg}^{-1}$ (maior dose de B aplicada). Os resultados confirmaram a necessidade de se adequar criteriosamente a dose de B a ser usada para a cultura da roseira.

Os teores de clorofila total diminuíram a partir da dose estimada de 9,54 $\mathrm{mg} \mathrm{kg}^{-1}$ de B (Figura 1e), o que coincidiu com o aparecimento de clorose em decorrência da toxidez causada pela dose elevada de B. Em plantas de Cucurbita pepo, um dos primeiros efeitos da toxidez por causa do excesso de B foi a redução nos teores de clorofila, o que antecedeu ao aparecimento dos sintomas visuais de toxidez (Lovatt \& Bates, 1984).
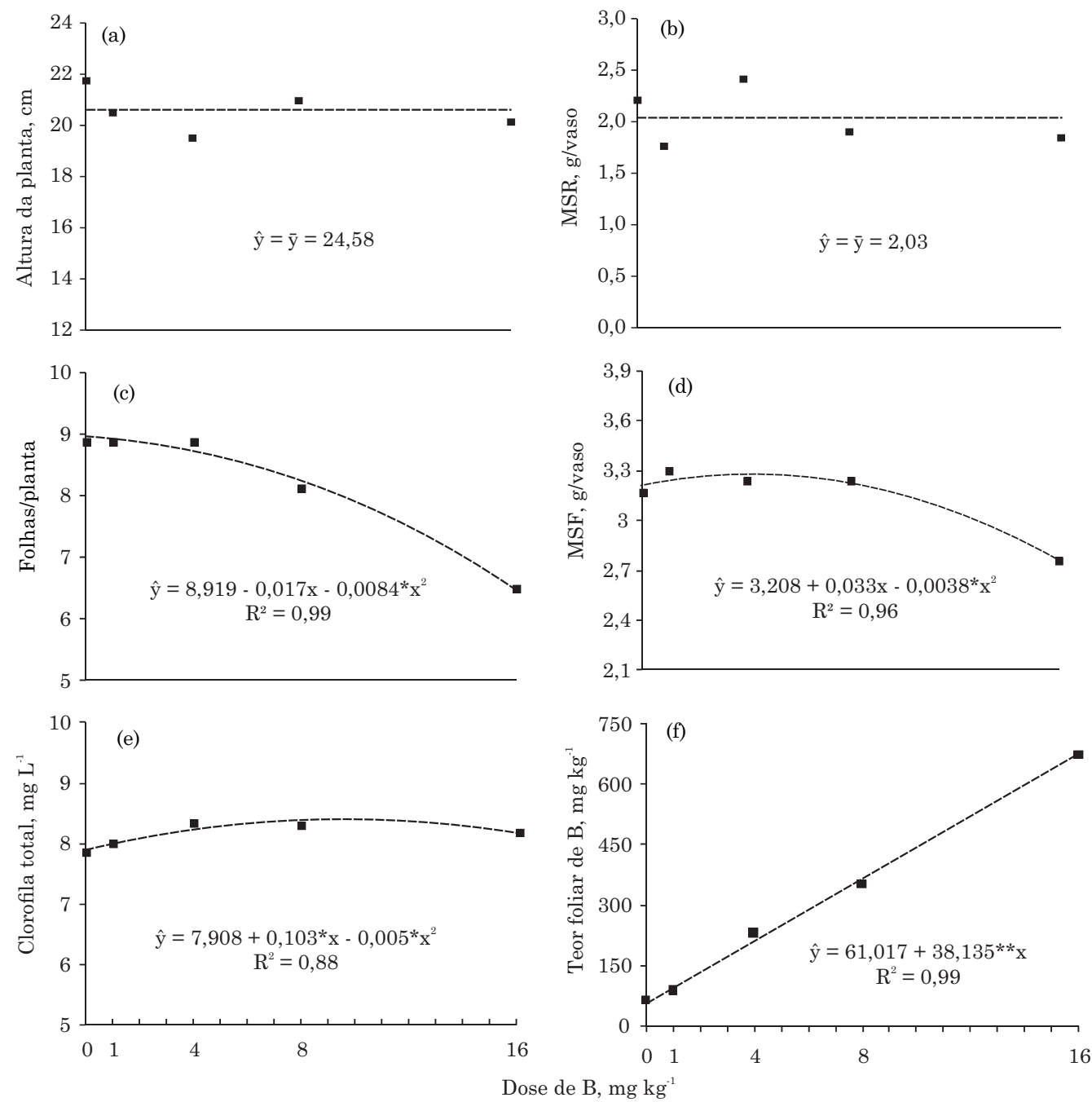

Figura 1. Altura da planta (a), produção de matéria seca de raízes (b), número de folhas por haste floral (c), produção de matéria seca de folhas (d), teor de clorofila total (e) e teor foliar de B (f) de roseira (cv. Shiny Terrazza $\left.{ }^{\circledR}\right)$, em função da aplicação de doses de B no substrato. ** $\mathrm{e}^{*}$ : significativo a 1 e a $5 \%$, respectivamente, pelo teste $t$. 
Segundo Reid et al. (2004), um dos efeitos fisiológicos provocados pela toxidez provocada pelo excesso de B inclui baixos teores de clorofila nas folhas. Tepe \& Aydemir (2011) também verificaram redução nos teores de clorofila em razão do excesso de B em lentilha e cevada.

Os teores foliares de B ajustaram-se ao modelo linear em função das doses de B, quanto maior a dose aplicada ao substrato maiores os teores de B nas folhas, atingindo-se $675 \mathrm{mg} \mathrm{kg}^{-1}$ (Figura 1f) nas folhas das plantas cujo substrato recebeu a maior dose de B (16 mg kg-1). No tratamento sem a adição de B ao substrato, seus teores foliares chegaram a $65 \mathrm{mg} \mathrm{kg}^{-1}$, valor acima da faixa considerada adequada para produção de rosas (30-60 mg kg-1) (Martinez et al., 1999). Considerando que na dose zero o substrato supriu o B requerido pelas plantas e, ainda assim, com o aumento da dose de B adicionada ao substrato houve resposta positiva das plantas, ficou evidente a exigência da cultivar Shiny Terrazza ${ }^{\circledR}$ quanto ao aporte desse micronutriente. Deve-se ressaltar que o teor de B considerado adequado para o desenvolvimento de uma cultura é variável e essa variação é atribuída a diferenças na composição química da parede celular, as quais ocorrem entre espécies e entre cultivares na mesma espécie (Marschner, 1995). Assim, o manejo correto da adubação, com a recomendação da dose adequada de B, para cada cultivar, pode ser um diferencial para maior ganho do produtor.

O número de dias para o florescimento diferiu em função das doses de B aplicadas, havendo diminuição desse período até a dose estimada de $8,6 \mathrm{mg} \mathrm{kg}^{-1} \mathrm{de} \mathrm{B}$, em que foi obtido o valor mínimo (41,2 d) (Figura 2a). $A$ adubação com $B$ antecipou aproximadamente cinco dias o florescimento das roseiras, podendo o manejo adequado da adubação contribuir para antecipar o ciclo dessas, dependendo do interesse do floricultor. Ahmad et al. (2010), avaliando a aplicação foliar de micronutrientes em três cultivares de roseira, também verificaram redução do número de dias para o florescimento em aproximadamente $6 \mathrm{~d}$, com a aplicação de B.

O comprimento do botão floral foi significativamente influenciado pelo $\mathrm{B}$ adicionado ao substrato e atingiu valor máximo de $2,79 \mathrm{~cm}$ com a dose de $9,08 \mathrm{mg} \mathrm{kg}^{-1}$ de B (Figura 2b). Da mesma forma, o diâmetro das flores respondeu aos tratamentos, evidenciando ajuste no modelo quadrático em função das doses de $\mathrm{B}$ aplicadas, sendo o maior diâmetro floral $(8,6 \mathrm{~cm})$ obtido com a dose de $8,7 \mathrm{mg} \mathrm{kg}^{-1}$ de B (Figura 2c). Aumento do diâmetro floral em relação à testemunha também foi observado por Ahmad et al. (2010) em três cultivares de roseira, após a aplicação foliar de B.

A produção de matéria seca de flores respondeu à aplicação das doses de B alcançando o valor máximo simulado pelo ajuste $(1,45 \mathrm{~g} /$ planta) com a dose de $7,5 \mathrm{mg} \mathrm{kg}{ }^{-1}$ (Figura 2d). No entanto, a dose de máxima eficiência econômica $(95 \%$ da produção máxima) foi $2 \mathrm{mg} \mathrm{kg}{ }^{-1}$ de $\mathrm{B}$ (produção de $1,38 \mathrm{~g} /$ planta). Em Minas Gerais, para a cultura da rosa, são recomendados 1,65 $\mathrm{kg} \mathrm{ha}^{-1}$ de B (CFSEMG, 1999), o que equivale a aproximadamente $0,83 \mathrm{mg} \mathrm{kg}^{-1}$. A constatação de resposta positiva com a dose de $2 \mathrm{mg} \mathrm{kg}^{-1}$ de B, com aumento da produção de matéria seca de flores nas roseiras da cultivar Shinny Terrazza ${ }^{\circledR}$, evidenciou que a recomendação da CFSEMG (1999) pode estar subestimando o B necessário para esse cultivar. Os resultados deste trabalho indicaram a dose $4 \mathrm{~kg} \mathrm{ha}^{-1}$ de $\mathrm{B}$, para se obter máxima eficiência econômica para o cultivar Shinny Terrazza ${ }^{\circledR}$.

O número de flores por planta, média de 1,85 por haste floral (Figura 2e), e a longevidade floral, média de 7,3 dias (Figura 2f), não diferiram em resposta às doses de B aplicadas ao substrato. Já a produção de matéria seca de folhas e flores, assim como o número de folhas nas plantas crescidas em substrato adubado com $16 \mathrm{mg} \mathrm{kg}{ }^{-1}$ de $\mathrm{B}$, foi menor em comparação às roseiras de vaso que não receberam adubação boratada (Figuras 1c-d e 2d), evidenciando o efeito tóxico da maior dose de B avaliada. Segundo Reid (2007), o excesso de $\mathrm{B}$ pode produzir diferentes efeitos, entre esses a redução na divisão celular nas raízes e nos teores de clorofila, lignina e suberina. O excesso de B também reduz a fotossíntese (Ardic et al., 2009; Guidi et al., 2011; Chen et al., 2012). Todos esses efeitos, consequentemente, reduzem o crescimento e florescimento (Reid, 2007).

Foram observados sintomas visuais de toxidez em razão do excesso de B, a partir da dose de $4 \mathrm{mg} \mathrm{kg}^{-1}$ do elemento (Figura 3). Esses sintomas começaram sete dias após a aplicação das doses de B, sendo observados, primeiramente, no tratamento com a maior dose (16 $\left.\mathrm{mg} \mathrm{kg}^{-1}\right)$ e apenas nas folhas mais velhas. Essa predominância dos sintomas nas folhas pertencentes à metade inferior da parte aérea das plantas ocorreu até o término do experimento. Esses sintomas iniciaram como pontos, semelhantes a manchas de encharcamento, primeiramente no ápice do limbo, coalescendo posteriormente para tomar as margens do limbo foliar. Junto com a coalescência surgiu uma clorose nas folhas, que evoluiu rapidamente para necrose e queda delas. A localização desses sintomas reflete a distribuição de B na maioria das espécies, com seu acúmulo ocorrendo nas partes da planta onde tem lugar o fluxo final da transpiração (Nable et al., 1997; Roessner et al., 2006). Manchas isoladas no limbo foliar também apareceram, principalmente com a aplicação de $16 \mathrm{mg} \mathrm{kg}^{-1}$ de B.

Na dose de $4 \mathrm{mg} \mathrm{kg}^{-1}$ de B, os sintomas foram mais brandos (Figura 3) aparecendo e evoluindo cerca de 25 dias após a aplicação do B ao substrato, com ocorrência de desfolhamento das plantas. A toxidez de B apareceu somente nas folhas mais velhas, confirmando sua baixa mobilidade nas plantas. Sintomas de toxidez de B semelhantes aos encontrados para a roseira neste trabalho são descritos em culturas 

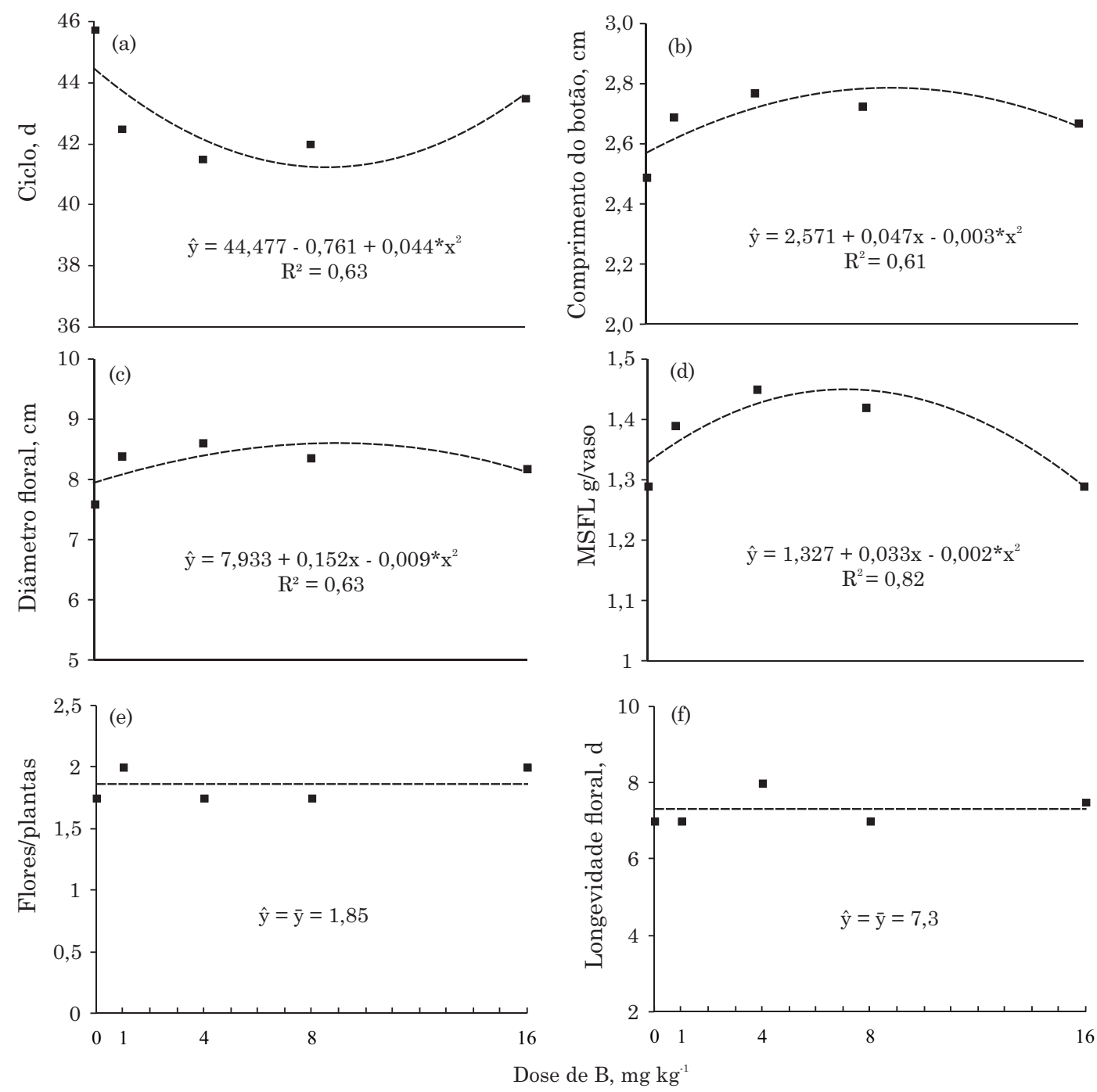

Figura 2. Número de dias para o florescimento (ciclo) (a), comprimento do botão (b), diâmetro floral (c), produção de matéria seca de flores (d), número de flores por planta (e) e longevidade floral (f) de roseira (cv. Shiny Terrazza $^{\circledR}$ ), em função da aplicação de doses de B no substrato. *: Significativo a $5 \%$ pelo teste $t$.

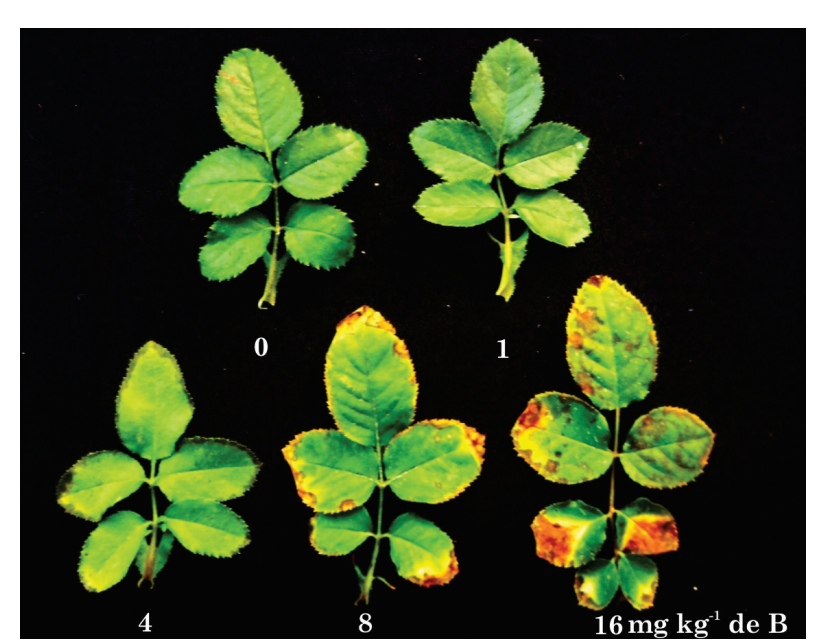

Figura 3. Sintomas de toxidez causados por B em folhas maduras de roseira (cv. Shiny Terrazza $\left.^{\circledR}\right)$, a partir da dose de $4 \mathrm{mg} \mathrm{kg}^{-1}$ desse nutriente. como algodão, alho, cebola, goiaba e mamona (Francois, 1991; Salvador et al., 2003; Silva, 2007; Ahmed et al., 2008).

As roseiras com sintomas de toxidez apresentaram teores foliares de B, variando de 271 a $675 \mathrm{mg} \mathrm{kg}^{-1}$. Segundo Marschner (1995), o limite crítico para a toxidez de B varia acentuadamente entre espécies, sendo $100 \mathrm{mg} \mathrm{kg}^{-1}$ para soja e milho, $400 \mathrm{mg} \mathrm{kg}^{-1}$ para pepino e $1.000 \mathrm{mg} \mathrm{kg}^{-1}$ para abóbora. Nas plantas que não receberam aplicação do $\mathrm{B}$, não foram observados sintomas visuais de deficiência desse nutriente.

\section{CONCLUSÕES}

1. A toxidez por causa do B, na roseira (cv. Shiny Terrazza $\left.{ }^{\circledR}\right)$, ocorreu a partir da aplicação da dose $4 \mathrm{mg} \mathrm{kg}^{-1}$ ao substrato. 
2. Os sintomas de toxidez foram caracterizados por manchas do tipo encharcamento, iniciadas pelas margens do limbo foliar, evoluindo para clorose e posterior necrose nas manchas. Apareceram com teores acima de $200 \mathrm{mg} \mathrm{kg}^{-1} \mathrm{~B}$ na matéria seca das folhas, sendo normais os teores na faixa de 65 a $89 \mathrm{mg} \mathrm{kg}^{-1}$.

3. A adubação com B aumentou a produção e a qualidade das flores da roseira (cv. Shiny Terrazza ${ }^{\circledR}$ ), diminuindo o número de dias para o seu florescimento. A dose de $\mathrm{Ba}$ ser adicionada ao substrato para obtenção da máxima eficiência econômica para esse cultivar foi $2 \mathrm{mg} \mathrm{kg}^{-1}$.

\section{LITERATURA CITADA}

AHMED, N.; ABID, M. \& AHMAD, F. Boron toxicity in irrigated cotton (Gossypium hirsutumL.). Pak. J. Bot., 40:24432452,2008 .

AHMAD, I.; KHAN, M.A.; QASIM, M.; AHMAD, R. \& RANDHAWA, M.A. Growth, yield and quality of Rosa hybrida as influenced by various micronutrients. Pak. J. Agric. Sci., 47:5-12, 2010.

ARDIC, M.; SEKMEN, A.H.; TOKUR, S.; OZDEMIR, F. \& TURKAN, I. Antioxidant response of chickpea plants subjected to boron toxicity. Plant Biol., 11:328-338, 2009.

BOLAÑOS, L.; LUKASZEWSKI, K.; BONILLA, I. \& BLEVINS, D. Why boron? Plant Physiol. Biochem., 42:907-912, 2004.

CAMACHO-CRISTÓBAL, J.J.; REXACH, J. \& GONZÁLEZFONTES, A. Boron in plants: Deficiency and toxicity. J. Integr. Plant Biol., 50:1247-1255, 2008.

CHEN, L.S.; HAN, S.; QI, Y.P. \& YANG, L.T. Boron stresses and tolerance in citrus Afr. J. Biotechnol., 11:5961-5969, 2012.

COMISSÃO DE FERTILIDADE DO SOLO DO ESTADO DE MINAS GERAIS - CFSEMG. Recomendações para uso de corretivos e fertilizantes em Minas Gerais: $5^{\text {a }}$ aproximação, Viçosa, MG, 1999. 360p.

CUSHMAN, L.C.; PEMBERTON, H.B. \& KELLY, J.W. Cultivar, flower stage, silver thiosulfate and BA interactions affect performance of potted miniature roses. HortScience, 29:805-808, 1994.

DECHEN, A.R. \& NACHTIGALL, G.R. Micronutrientes. In: FERNANDES, M.S., ed. Nutrição mineral de plantas. Viçosa, MG, Sociedade Brasileira de Ciência do Solo, 2006. p.327-354.

DORDAS, C. \& BROWN, P.H. Permeability of boric acid across lipid bilayers and factors affecting it. J. Membr. Biol., 175:95-105, 2000.

FAGERIA, N.K. Níveis adequados e tóxicos de boro na produção de arroz, feijão, milho, soja e trigo em solo de cerrado. R. Bras. Eng. Agric. Amb., 4:57-62, 2000.

FRANCOIS, L.E. Yield and quality responses of garlic and onion to excess boron. HortScience, 26:547-549, 1991.
GOLDBACH, H.E.; YU, Q.; WINGENDER, R.; SCHULZ, M.; WIMMER, M.; FINDEKLEE, P. \& BALUSKA, R. Rapid response reactions of roots to boron deprivation. J. Plant Nutr. Soil Sci., 164:173-181, 2001.

GONÇALVES, J.L.M. \& VALERI, S.V. Micronutrientes para culturas: Eucalipto e pinus. In: FERREIRA, M.E.; CRUZ, M.C.P.; RAIJ, B.van \& ABREU, C.A., eds. Micronutrientes e elementos tóxicos na agricultura. Jaboticabal, CNPq/ FAPESP/Potafos, 2001. p.393-423.

FURLANI, A.M.C.; CARVALHO, C.P.; FREITAS, J.G. \& VERDIAL, M.F.V. Wheat cultivar tolerance to boron deficiency and toxicity in nutrient solution. Sci. Agric., 60:359-370, 2003.

GUIDI, L.; DEGL'INNOCENTI, E.; CARMASSI, G.; MASSA, D. \& PARDOSSI, A. Effects of boron on leaf chlorophyll fluorescence of greenhouse tomato grown with saline water. Environ. Exp. Bot., 73:57-63, 2011.

GUPTA, U.C. Boron and its role in crop production. Boca Raton, CRC Press, 1993. 237p.

GUPTA, U.C. Boron deficiency and toxicity symptoms for several crops as related to tissue boron level. J. Plant Nutr., 6:387-395, 1983.

HAVLIN, J.L.; BEATON, J.D.; TISDALE, S.L. \& NELSON, W.L. Soil fertility and fertilizers. 7.ed. Upper Saddle River, Pearson Education, 2005. 515p.

LOVATT, C.J. \& BATES, L.M. Early effects of excess boron on photosynthesis and growth of Cucurbita pepo. J. Exp. Bot., 35:297-305, 1984.

MARIANO, E.D.; FAQUIN, V.; FURTINI NETO, A.E.; ANDRADE, A.T. \& MARIANO, I.O. Níveis críticos de boro em solos de várzea para o cultivo do feijoeiro. Pesq. Agropec. Bras., 35:1637-1644, 2000.

MARSCHNER, H. Mineral nutrition of higher plants. 2.ed. San Diego, Academic, 1995. 902p.

MARTINEZ, H.E.P.; CARVALHO, J.G. \& SOUZA, R.B. Diagnose foliar. In: RIBEIRO, A.C.; GUIMARÃES, P.T.G. \& ALVAREZ V., V.H., eds. Recomendação para uso de corretivos e fertilizantes em Minas Gerais: $5^{\text {a }}$ Aproximação. Viçosa, MG, Comissão de Fertilidade do Solo do Estado de Minas Gerais. 1999. p.143-168.

NABLE, R.O.; BAÑUELOS, G.S. \& PAULL, J.G. Boron toxicity. Plant Soil, 193:181-198, 1997.

NELL, T.A.; BARRET, J.E. \& LEONARD, R.T. Production factor affecting post production quality of flowering potted plants. HortScience, 32:817-819, 1997.

PORRA, R.J.; THOMPSON, W.A. \& KRIEDERMANN, P.E. Determination of accurate extinction coefficients and simultaneous equation for assaying chlorophylls $a$ and $b$ extracted with four different solvents: Verification of the concentration of chlorophylls standards by atomic absorption spectroscopy. Biochim. Biophys. Acta, 975:384394, 1989. 
REID, R.J. Identification of boron transporter genes likely to be responsible for tolerance to boron toxicity in wheat and barley. Plant Cell Physiol., 48:1673-1678, 2007.

REID, R.J.; HAYES, J.E.; POST, A.; STANGOULIS J.C.R. \& GRAHAM, R.D. A critical analysis of the causes of boron toxicity in plants. Plant Cell Environ., 25:1405-1414, 2004.

ROESSNER, U.; PATTERSON, J.H.; FORBES, M.G.; FINCHER, G.B.; LANGRIDGE, P. \& BACIC, A. An investigation of boron toxicity in barley using metabolomics. Plant Physiol., 142:1087-1101, 2006.

SALVADOR, J.O.; MOREIRA, A.; MALAVOLTA, E. \& CABRAL, C.P. Influência do boro e do manganês no crescimento e na composição mineral de mudas de goiabeira. Ci. Agrotecnol., 27:325-331, 2003.

SAVVAS, D. General Introduction. In: SAVVAS, D. \& PASSAM, H.C., eds. Hydroponic production of vegetables and ornamentals. Athens, Embryo Publications, 2002. p.1523 .

SHELP, B.J. \& BROWN, P.H. Boron mobility in plants. Physiol. Plant., 94:356-361, 1995.
SILVA, D.H. Boro em mamoneira: Aspectos morfológicos e fisiológicos relacionados à deficiência e toxicidade. Piracicaba, Centro de Energia Nuclear na Agricultura, 2007. 103p. (Dissertação de Mestrado)

SILVA, F.A.S. \& AZEVEDO, C.A.V. A new version of the Assistat-Statistical Assistance Software. In: WORLD CONGRESS ON COMPUTERS IN AGRICULTURE, 4., Orlando, 2006. Anais... Orlando, American Society of Agricultural and Biological Engineers, 2006. p.393-396.

SONNEVELD, C. \& ELDEREN, C.W. Chemical analysis of peaty growing media by means of water extraction. Commun. Soil. Sci. Plant Anal., 25:3199-3208, 1994.

TEPE, M. \& AYDEMIR, T. Antioxidant responses of lentil and barley plants to boron toxicity under different nitrogen sources. Afr. J. Biotechnol., 10:10882-10891, 2011.

WOLF, B. Improvents in the azomethine-H method for determination of boron. Commun. Soil Sci. Plant Anal., 5:39-44, 1974.

ZANÃO JÚNIOR, L.A.; FONTES, R.L.F. \& ÁVILA, V.T. Aplicação do silício para aumentar a resistência do arroz à mancha-parda. Pesq. Agropec. Bras., 44:303-206, 2009. 